\title{
O falso conflito \\ entre atividade física e \\ asma
}

Prof ${ }^{u}$ Irene C Rangel Betti

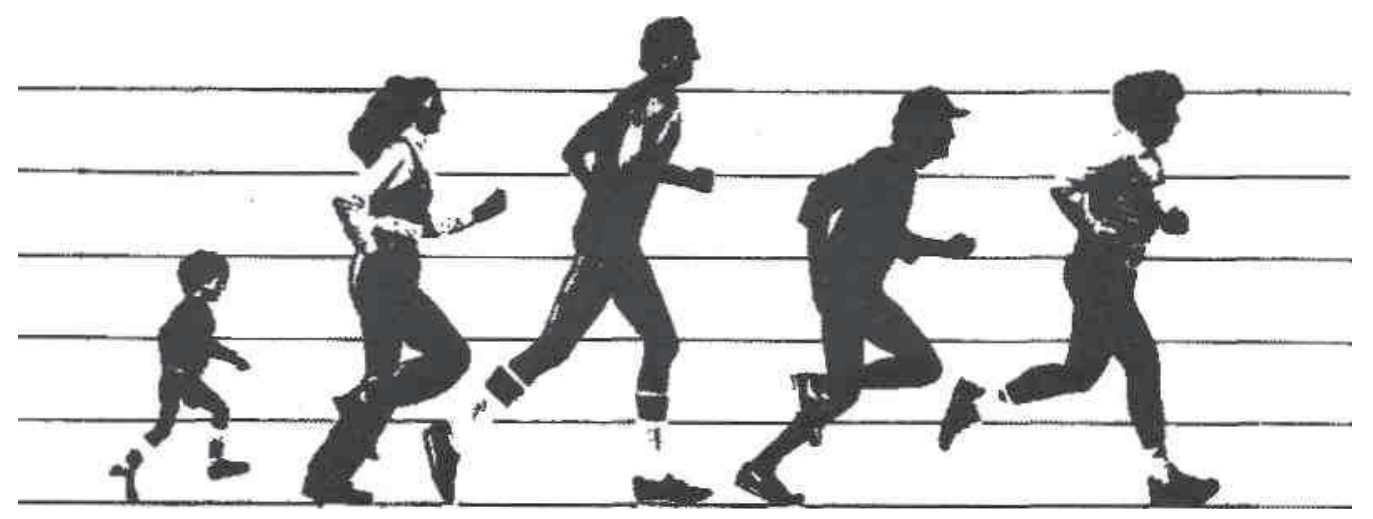

O indivíduo portador de asma brônquica geralmente vive em precárias condições físicas porque sente-se limitado para a prática ou, no caso de crianças asmáticas, são superprotegidas pelos pais e privadas de atividades. Muitas crianças são, até mesmo, dispensadas das aulas de educação física.

Entretanto, existe a possibilidade destes indivíduos receberem os benefícios das atividades físicas através da ginástica respiratória e natação. Ao contrário do que se imagina, a atividade física, quando bem controlada, pode diminuir o número e a intensidade das crises de asma. Os profissionais de educação física precisam conhecer esta modalidade, para que possam auxiliar cada vez mais os portadores de asma brônquica. 
urante certo tempo a atividade física foi negligenciada e até mesmo negada, nas escolas, a portadores de asma (Goldman et al, 1966). Ainda hoje encontramos médicos

que dispensam crianças asmáticas destas aulas. Isto pode ser compreendido de duas formas, por um lado o receio de que o profissional de educação física não saiba lidar com o asmático, por outro a crença de que a atividade física possa prejudicar o asmático portador de AIE (asma induzida por exercício). A asma-brônquica é uma síndrome do aparelho respiratório causada por inúmeros fatores, dos quais o componente alérgico parece ser o mais comum (por exemplo: pó, mofo, cheiros fortes, pelos e penas, etc.). Os indivíduos que possuem um fator hereditário estão sujeitos a uma crise asmática em qualquer época da vida, sendo que as crises são mais freqüentes na infância.

Uma crise é definida como uma hiper-reatividade traqueo-brônquica de caráter reversível, ou seja, acomete o indivíduo que passa a apresentar um quadro de tosse, sibilos (chiado) e dispnéia. Geralmente ela desaparece após 3 a 5 dias (Cecil, 1984). Normalmente, a tosse apresenta-se com muco (catarro), mas pode apresentar-se também como uma tosse seca.

Os objetivos deste artigo são: a) justificar a necessidade que todo asmático possui de, como qualquer indivíduo, praticar uma atividade física; b) tentar desmitificar a crença de que o asmático, inclusive o possuidor de AIE, não pode beneficiar-se da atividade física; c) tentar clarificar a confusão existente entre AIE e o cansaço sentido pelo asmático após uma atividade, que aliás é o mesmo sentido por qualquer indivíduo.

\section{DESENVOLVIMENTO}

asmático crônico está freqüentemente em precária condição física, causada por inatividade, apresentando inclusive um subdesenvolvimento físico.

Uma das razões de se evitar as atividades físicas para a criança asmática é a superproteção. As mães, principalmente, ao tentarem proteger seus filhos, acabam privando-os de muitas coisas e atividades. Entre elas citamos o gelado (sorvetes, qualquer tipo de líquido gelado, gelo, etc.); o sereno; a criança vive super agasalhada, não pode andar descalça, abrir geladeira ou retirar a camiseta. Isto é facilmente explicado pelo fato de que as crises asmáticas geralmente vêm acompanhadas de febre, tosse $\mathrm{e}$ infecções das amígdalas. Como este quadro é também comum a uma gripe, as mães, na intenção de protegerem seus filhos, tentam evitá-la, impedindo que a criança tome gelados, ande descalça, etc.

No entanto, nem sempre um quadro de gripe evolui para uma crise asmática e, por vezes, como a criança acaba não adquirindo resistência orgânica, ao primeiro contato com um sorvete, por exemplo, realmente tem uma gripe. Na realidade, fora de crise, o asmático deve levar uma vida normal como qualquer criança. As atividades físicas são também relacionadas à crise, na medida que o cansaço apresentado é parecido com a dispnéia (aumento da freqüência respiratória), uma das características da crise de asma-brônquica. Estas atividades são as responsáveis por um desenvolvimento harmônico do indivíduo (Henriksen \& Nielsen, 1983) e como tal não podem ser dispensadas. O que acontece a uma criança asmática impedida de correr, andar de bicicleta ou praticar qualquer atividade física é o mesmo que acontece com qualquer indivíduo privado destas atividades, ou seja, um subdesenvolvimento que pode trazer várias conseqüências como musculatura subdesenvolvida, falta de coordenação motora e falta de resistência orgânica. 
Asma induzida por exercício

Há aproximadamente 300 anos, o exercício físico é tido como um agente desencadeador de crise de dispnéia ou broncoconstricção (Meyer, Saute \& Winge, 1987). Este quadro é conhecido como asma induzida por exercício (AIE) ou broncoespasmo induzido por exercício (BIE). Geralmente o ataque de AIE ocorre entre 3 a 5 minutos após um exercício contínuo, de moderado a intenso, para crianças, e de 6 a 8 minutos após para o adulto (Ancic, 1982). A severidade do exercício é um importante fator que deve ser observado. Um exercício com consumo máximo de 02 a $85 \%$ produz maior broncoconstricção (Voy, 1985). Testes com bicicleta ergométrica, com freqüência cardíaca de 80 a $90 \%$ do máximo predito, por 6 a 8 minutos são capazes de detectar AIE em indivíduos com suspeita da enfermidade (Meyer Neto et al., 1989). A broncoconstrição ocorre após o término do exercício, sendo que durante os primeiros minutos ocorre a broncodilatação (observada tanto nos indivíduos normais quanto nos asmáticos) e, após o término do exercício, há um início gradual de broncoespasmo (Meyer, Saute \& Winge, 1987). Há uma resolução espontânea da crise após 30 a 60 minutos sem tratamento, raramente exigindo medicação para sua resolução. Ou seja, nos portadores de AIE a crise em si é diferente da crise para causas alérgicas ou emocionais, que duram em média de 3 a 5 dias.

Muitos autores indicam que a utilização de drogas B2-adrenérgicas por via inalatória pode vir a beneficiar o asmático com AIE, quando ministradas antes do início de qualquer atividade física (Anderson et al., apud Meyer Neto et al., 1989). Estes autores citam também a atividade física como capaz de trazer benefícios para o portador de AIE. Bundgaard (1985), realizou um estudo com 28 crianças asmáticas participantes de um treinamento físico durante seis semanas. Neste grupo, a função pulmonar de repouso e o lactato plasmático pós-exercício estavam mais baixos pelo efeito do treinamento, sendo que no grupo controle de 14 crianças a broncoconstrição e a forma física permaneceram inalterados. Em Betti \& Barbosa (1992), foram encontrados resultados demonstrando que, fisiologicamente, as funções pulmonares são inalteradas, permanecendo um mistério, mas o asmático beneficia-se física, social e emocionalmente de programas de atividades físicas.

Noite (1983), considera que os indivíduos portadores de asma jamais devam disputar os primeiros lugares em competições. Entretanto, exemplos de sucesso em competições nacionais e internacionais mostram-nos o contrário. É surpreendente afirmar que, nos Jogos Olímpicos de Los Angeles, o Comitê Olímpico dos E.U.A. identificou 67 entre os 597 atletas olímpicos com asma ou asma induzida por exercício (Voy, 1985). Destes, 41 ganharam medalhas de ouro, prata ou bronze. O único episódio considerado triste foi o do atleta Rick DeMont, norteamericano que ficou mundialmente conhecido quando nesta mesma olimpíada foi desclassificado, perdendo sua medalha de ouro, por haver ingerido efedrina, uma droga utilizada no tratamento de crises asmáticas, mas proibida pelo comitê antidoping. Falhas como esta não mais acontecem (Meisenheimer Jr., 1983; Voy, 1985). Estes exemplos mostram-nos que o asmático também pode ser capaz de vencer esportes de competição.

Para os que não almejam ser campeões, mas pretendem ter uma vida normal, a recomendação da atividade física continua sendo válida, mesmo para os que possuem história de asma induzida por exercício (Meisenheimer Jr., 1983). Landau (1979), afirma ser da maior importância que as crianças com asma sejam "... tão fisicamente ativas quanto possível"(p.585). Muitas vezes as atividades físicas são evitadas para as crianças com AIE (Henriksen \& Nielsen, 1983); as mães, ao perceberem que seus filhos entram em crise após uma corrida ou outro exercício mais intenso, acabam por proibir a criança de participar de brincadeiras que incluam estas características (Meyer et al., 1987).

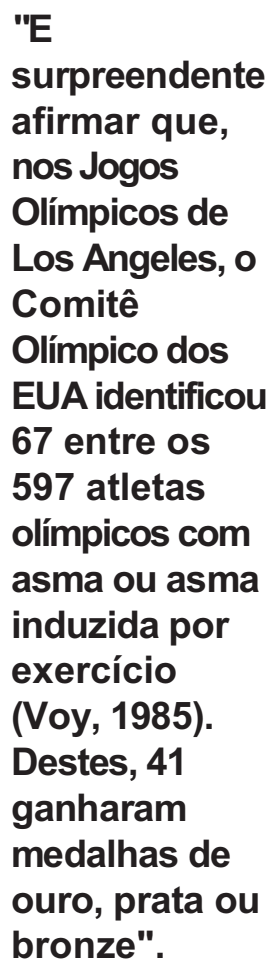




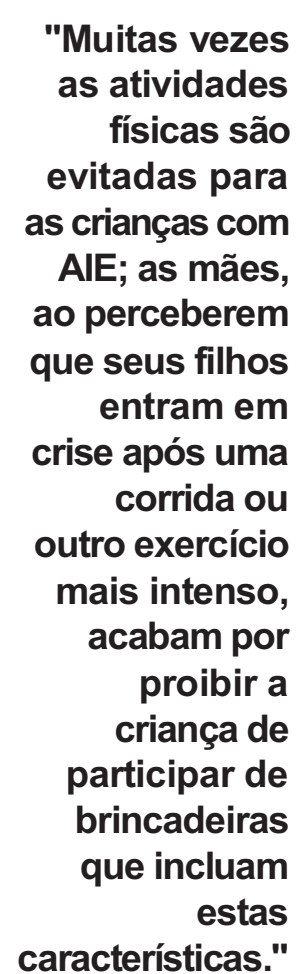

No já citado exemplo das Olimpíadas de Los Angeles em 1984, os 67 atletas diagnosticados com AIE apresentaram-se em 29 eventos diferentes, comprovando que o asmático pode perfeitamente participar de diversos tipos de exercícios e até mesmo de esportes de competição (Voy, 1985).

Toda atividade física deve ser bem dosada e controlada, não só para os asmáticos como também para todo o indivíduo. Apesar da natação ser considerada como a melhor atividade física para o portador de asma, esta não controla uma crise e, neste ponto, outra atividade, capaz de controlar uma crise ou até mesmo abortá-la, deve ser utilizada, ou seja, a ginástica respiratória, onde é dada ênfase ao controle voluntário do ato respiratório (Nieto et al, 1979).

\section{Ginástica respiratória}

O italiano C. Forlalini parece ter sido o precursor da ginástica respiratória, propondo-a como profilaxia e tratamento da tuberculose pulmonar. Esta ginástica ou reeducação respiratória foi inicialmente ministrada somente por fisioterapeutas, cujo processo, até hoje, continua sendo individual e muitas vezes oneroso.

O trabalho em grupo, no qual o enfoque é mais global, trabalhando o indivíduo como um todo, foi iniciado no Brasil pelo professor Progresso Nieto (César, 1981), sem perder no entanto as características individuais da ginástica respiratória, uma ventilação mais eficaz, uma adequada mobilidade articular da caixa toráxica e da cintura escapular, profilaxia e tratamento de vícios posturais, resistência geral e auto confiança (Nieto et ai, 1979). A autoconfiança parte da segurança adquirida no decorrer do trabalho, relacionada ao controle da respiração que a criança adquire e à conscientização da família, que passa a tratar a criança normalmente, sem protegê-la (César, 1981).

A ginástica respiratória é constituída de atividades físicas aeróbicas, com o controle da respiração durante todos os exercícios. A inspiração é nasal, com ênfase na expiração que é mais longa. O controle da fase expiratória é conseguido através de uma pressão consciente intra-abdominal sobre $o$ músculo diafragma, principal músculo da respiração (Lapierre, 1982; Maccagno, 1973; Nieto et ai, 1979). No exercício respiratório o asmático deve inspirar pelo nariz e expirar pela boca (produzindo ou não sons).

Em Nieto et ai, (1979) encontramos a definição de exercício respiratório, a partir dos estudos de Maccagno (1973):

"Como exercício respiratório aplicado ao portador de asmabrônquica, compreendemos o ato de inspirar pelo nariz e expirar pela boca, auxiliando a expiração pela contração dos músculos abdominais e fazendo-a mais prolongada que a inspiração "(p.9).

Este exercício pode ser efetuado com a ajuda dos pais, através de uma pressão sobre as últimas costelas na fase de expiração. Quando em crise, o asmático utiliza também a musculatura acessória da respiração, tornando-se um hipertenso. Muitas das deformidades da caixa toráxica, citadas anteriormente, são devidas a uma má respiração. Ao professor de educação física cabe conscientizar os pais das possíveis deformações e atuar sobre os problemas funcionais (sem agressão óssea). Quanto aos problemas estruturais, o trabalho deverá ser de reforço e relaxamento muscular, o que pode beneficiar o indivíduo não agravando o problema, mas sua redução é impossível (Nieto et al., 1979). Com o crescimento, muitas vezes o problema pode passar desapercebido, apesar de existir.

Natação

A natação é reconhecida como exercício físico menos asmagênico que os demais exercícios (Fitch et al., 1976; Meisenheimer Jr., 1983; Pituch \& Bruggeman, 1982), sendo, portanto, a mais recomendada pelos médicos desde a antigüidade. Os ob- 

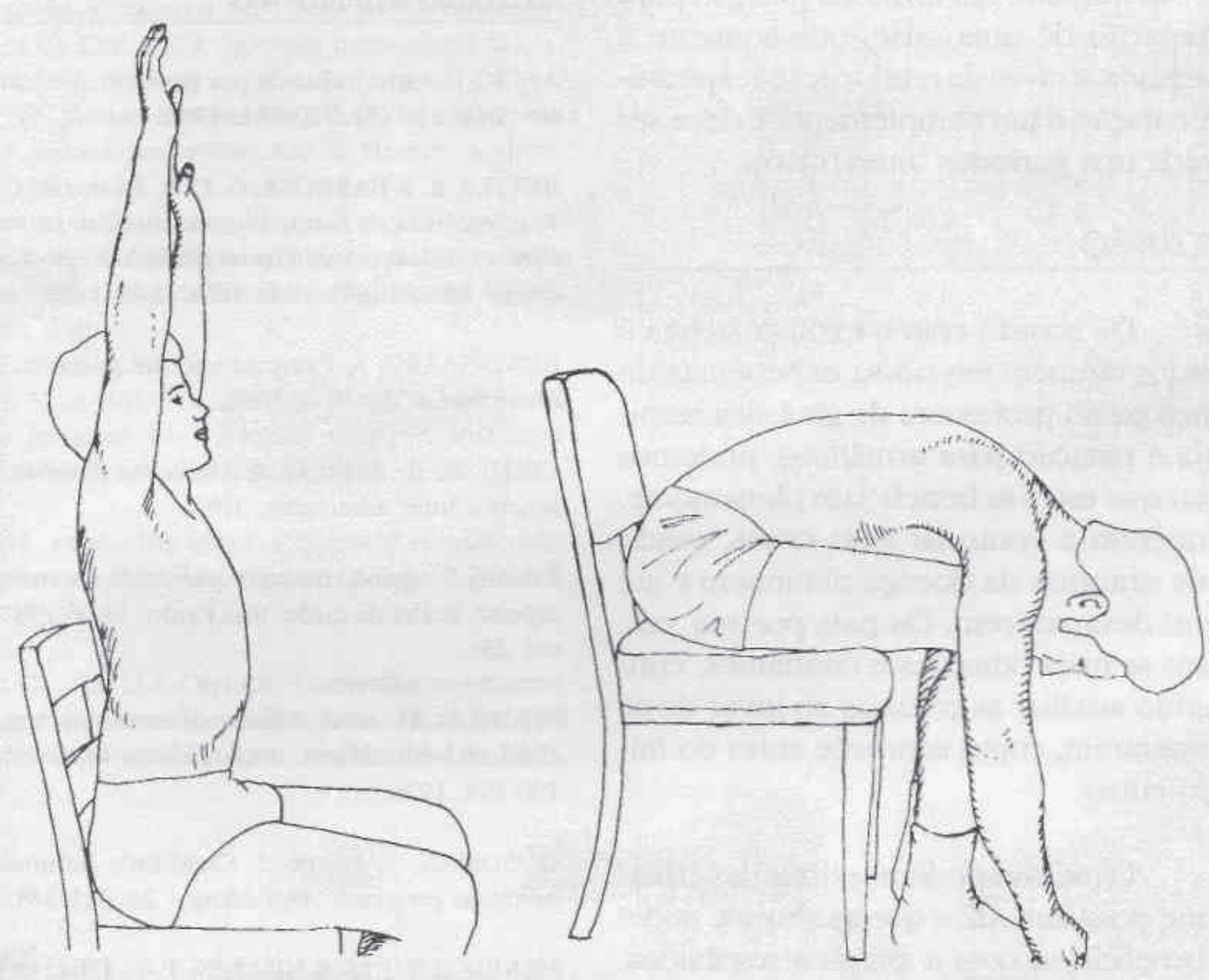

jetivos de um trabalho em natação para crianças asmáticas são: o desenvolvimento das qualidades físicas, o relaxamento, controle respiratório e corporal e o aprendizado e aperfeiçoamento de habilidades aquáticas, o desenvolvimento da resistência, do sistema muscular, do sistema cárdio-vascularrespiratório e a expansão pulmonar (Nieto et ai, 1979).

Para Pituch \& Bruggeman (1982) a natação contribui para fortalecer todos os músculos, especialmente o diafragma e os músculos respiratórios auxiliares. Sua utilização é recomendada, tendo em vista os seguintes fatores: controle eficiente da respiração, posição horizontal, pressão hidrostática, menor aumento da temperatura corporal e inalação de ar mais quente e úmido pelo vapor encontrado na superfície d'água e pelo ambiente, tanto da água quanto do local, serem mais temperados. Além deste fatores, são também considerados po1 Moisés (1989) o relaxamento e o trabalhc postural conseguido através da água.

Apesar de muito auxiliar na respiração, o treino da natação comum, da forma como é ministrada em escolas e clubes, não é capaz de auxiliar a criança a controlar uma crise. O que ocorre geralmente é uma maior resistência da criança. Vários programas $\mathrm{d} \epsilon$ natação fazem menção a natação especial. mas o que se vê é a aplicação da nataçãc convencional (Oliveira, 1988). Muitas crianças melhoram quando freqüentam programas que incluem a natação, porém os efeitos fisiológicos não são ainda totalmente conhecidos ou não se observaram mudanças significativas em seus parâmetros respiratórios (Fitch \& Morton, 1976; Sly et al., 1972; Pituck \& Bruggman, 1982).

De acordo com Moisés (1989) não 
"Podemos

afirmar que os

asmáticos se

beneficiam

plenamente,

aprendendo a

controlar suas

crises, sendo

que os

sintomas

diminuem e

até mesmo

desaparecem". basta um trabalho em torno da natação para a superação de uma crise, que somente é conseguida através da reeducação respiratória. A natação é um complemento e deve ser utilizada nos períodos intercríticos.

\section{CONCLUSÃO}

De acordo com o exposto acima e baseados também em nossa experiência de 15 anos como professora de ginástica respiratória e natação para asmáticos, podemos afirmar que estes se beneficiam plenamente, aprendendo a controlar suas crises, sendo que os sintomas da doença diminuem e até mesmo desaparecem. Os pais por sua vez, sentem-se mais otimistas e confiantes, conseguindo auxiliar as crianças ao invés de se desesperarem, como acontece antes do início do curso.

O mesmo podemos dizer das crianças que possuíam AIE e que igualmente puderam beneficiar-se com a ginástica respiratória. Suas crises diminuíram, elas aprenderam a controlar sua respiração e, principalmente, quando parar uma atividade que poderia thes causar uma crise. Outro benefício diz respeito aos problemas posturais que as crianças possuem. Apesar de muitos deles não regredirem, existe a possibilidade destes estacionarem e serem minimizados pelo crescimento da criança.

Os exemplos citados em relação aos atletas que participaram de olimpíadas mostramnos que os asmático pode participar de atividades física, desde que bem orientados, tanto por seu médico, quanto por um professor de educação física.

A nosso ver, portanto, a criança asmática não deve ser afastada da atividade física oferecida na escola e sim os professores de educação física podem e devem integrar-se do conteúdo da ginástica respiratória através de cursos e leituras, para que possam auxiliar os portadores de asma-brônquica, doença que, infelizmente, vem aumentando cada dia mais, principalmente pelo aumento da poluição atmosférica e outros fatores desencadeantes de crises.

\section{HERAASBBUCRÁACAS}

ANCIC, P. Asma inducida por ejercicio. Revista médica do Chile, 110 (7): 710-714, 1982.

BETTI, I. R. \& BARBOSA, G. O. S. Efeitos da Ginástica Respiratória e da Natação como auxiliar no tratamento de crianças asmáticas no periodo inter-crise. Anais da 44 Reunião anual da SBPC: 140, 1992.

BUNDGAARD, A. Exercise and the asthamatic. Sports Medicine. 2: 254-266, 1985.

CECIL, R. L. Tratado de Medicina Interna. Rio de Janeiro: Inter americana, 1984.

CÉSAR, F. Asma, doença que pode ser tratada pelo esporte. Folha da tarde. São Paulo. 19.06.1981. Esportes. 23.

FITCH, K. D. et al. Effects of swinning training on children with asthma. Arch. Disease in childhood, 51: 190-194, 1976.

GOLDMAN, S. L. et al. Children's asthmatic rehabilitation program. Ann allergy. 24: 345-348, 1966.

HENRIKSEN, J. M. \& NIELSEN, T. T. Effect of physical training on exercise-induced bronchoconstriction. Acta Paediatri Scand. 72: 31-36, 1983.

KRUMHOLZ, R. A. Rehabilitation of the chonic asthmatic. Comprehensive Therapy. 4: 38-41, 1978.

LANDAU, L. I. Avaliação e tratamento ambulatorial da asma. In: LEVISON, H. Clinicas Pediátricas da América do Norte. Rio de Janeiro: Inter americana, 1979-

LAPIERRE, A. A reeducação física. $6^{\text {a }}$ ed. São Paulo: Manole, 1982.

MACCAGNO, A. L. kinesiologia respiratória.Barcelona: JIWS, 1979

MEISENHEIMER Jr., J. Training asthmatic children Swimming Technique. 20 (1): 29-31, 1983.

MEYER, F. et al. Asma induzida pelo exercício. Aspectos fisiopatológicos e manejo, Jornal de Pediatria, 63 (2): 79-82, 1987.

MEYER NETO et al. Asma induzida por exercício. Revista Brasileira Clínica Terapêutica 18 (10): 409413, 1989.

MOISÉS, M. P. Os benefícios da natação e o portador de asma brônquica. Nadar. 17 (1): 8-11, 1989.

NIETO, P. et al.. Educação Física e a criança porta- 
dora de asma-brônquica. São Paulo: Escola de Educação Física da USP, 1979- (apostila mimeografada).

NOLTE, D. Asma: tratamento precoce e eficaz dos sintomas iniciais posteriores. Rio de Janeiro: Ao livro técnico, 1983-

OLIVEIRA, P. R. Análise crítica da natação como atividade capaz de curar a asma e a bronquite. Sprint. 05: 34-35, 1988

PITUCH, M. \& BRUGGEMAN, J. Lungs inlimited - A self-care program for asthmatic children and their families. Children Today. 23 (3): 28-35, 1982.

SLY, R. M. et al. The effect of physical conditioning upon asthmatic children. Annals os Allergy. 30: 86-93, 1972.

VOY, R. O. The U.S. Olympic Commttee experiense with exercise-induced bronchospasm. Medicine and Science in Sports and Exercise. 18 (3): 328-330, 1985.

\section{IMIIRMOS:}

Asma-brônquica, atividade física, ginástica

respiratória.

Prof ${ }^{\prime}$. Irene C. Rangel Betti

Prof ${ }^{u}$. do Departamento de Educação

Física, UNESP, Rio Claro - SP 